\section{OPEN ACCESS}

Edited by:

Alessio Squassina

University of Cagliari, Italy

Reviewed by:

George Foussias,

Center for Addiction and Mental Health (CAMH), Canada Arthur D. P. Mak,

The Chinese University of Hong Kong, China

*Correspondence: Christoph U. Correll ccorrel/@northwell.edu

Specialty section: This article was submitted to Neuroimaging and Stimulation, a section of the journal Frontiers in Psychiatry

Received: 02 June 2020 Accepted: 14 September 2020 Published: 21 October 2020

Citation:

Salazar de Pablo G, Guinart D, Cornblatt BA, Auther AM, Carrión RE, Carbon $M$, Jiménez-Fernández $S$, Vernal $D L$, Walitza S, Gerstenberg M, Saba R, Lo Cascio N, Brandizzi M, Arango C, Moreno C, Van Meter A, Fusar-Poli P and Correll CU (2020)

DSM-5 Attenuated Psychosis

Syndrome in Adolescents Hospitalized With Non-psychotic Psychiatric

Disorders.

Front. Psychiatry 11:568982. doi: 10.3389/fpsyt.2020.568982

\title{
DSM-5 Attenuated Psychosis Syndrome in Adolescents Hospitalized With Non-psychotic Psychiatric Disorders
}

\begin{abstract}
Gonzalo Salazar de Pablo ${ }^{1,2}$, Daniel Guinart ${ }^{3,4}$, Barbara A. Cornblatt ${ }^{3,4,5}$, Andrea M. Auther ${ }^{3,4}$, Ricardo E. Carrión ${ }^{3,4,5}$, Maren Carbon ${ }^{3}$, Sara Jiménez-Fernández ${ }^{6,7}$, Ditte L. Vernal ${ }^{8}$, Susanne Walitza ${ }^{9}$, Miriam Gerstenberg ${ }^{9}$, Riccardo Saba ${ }^{10}$, Nella Lo Cascio ${ }^{11}$, Martina Brandizzi ${ }^{12}$, Celso Arango ${ }^{2}$, Carmen Moreno ${ }^{2}$, Anna Van Meter ${ }^{3,4,5}$, Paolo Fusar-Poli ${ }^{1,13,14}$ and Christoph U. Correll ${ }^{3,4,5,15 *}$

${ }^{1}$ Early Psychosis: Interventions and Clinical-Detection (EPIC) Lab, Department of Psychosis Studies, Institute of Psychiatry, Psychology \& Neuroscience, King's College London, London, United Kingdom, ${ }^{2}$ Department of Child and Adolescent Psychiatry, Centro de Investigación Biomédica en Red de Salud Mental, General Universitario Gregorio Marañón School of Medicine, Institute of Psychiatry and Mental Health, Hospital Instituto de Investigación Sanitaria Gregorio Marañón (IISGM), Universidad Complutense, Madrid, Spain, ${ }^{3}$ Department of Psychiatry, The Zucker Hillside Hospital, Northwell Health, Glen Oaks, NY, United States, ${ }^{4}$ Department of Psychiatry and Molecular Medicine, Donald and Barbara Zucker School of Medicine at Hofstra/Northwell, Hempstead, NY, United States, ${ }^{5}$ Institute for Behavioral Science, The Feinstein Institutes for Medical Research, Manhasset, NY, United States, ${ }^{6}$ Child and Adolescent Mental Health Unit, Jaén Medical Center, Jaén, Spain, ${ }^{7}$ Department of Psychiatry, University of Granada, Granada, Spain, ${ }^{8}$ Research Unit for Child- and Adolescent Psychiatry, Aalborg University Hospital, Aalborg, Denmark, ${ }^{9}$ Psychiatric University Hospital Zurich, Department of Child and Adolescent Psychiatry and Psychotherapy, Zurich, Switzerland, ${ }^{10}$ Department of Mental Health, Rome, Italy, ${ }^{11}$ Prevention and Early Intervention Service, Department of Mental Health, Rome, Italy, ${ }^{12}$ Local Health Agency Rome 1, Santo Spirito in Sassia Hospital, Department of Mental Health, Inpatient Psychiatric Unit, Rome, Italy, ${ }^{13}$ Department of Brain and Behavioral Sciences, University of Pavia, Pavia, Italy, ${ }^{14}$ Outreach and Support in South London Service, South London and Maudsley National Health Service Foundation Trust, London, United Kingdom, ${ }^{15}$ Department of Child and Adolescent Psychiatry, Charité Universitätsmedizin, Berlin, Germany
\end{abstract}

Introduction: Although attenuated psychotic symptoms often occur for the first time during adolescence, studies focusing on adolescents are scarce. Attenuated psychotic symptoms form the criteria to identify individuals at increased clinical risk of developing psychosis. The study of individuals with these symptoms has led to the release of the DSM-5 diagnosis of Attenuated Psychosis Syndrome (APS) as a condition for further research. We aimed to characterize and compare hospitalized adolescents with DSM-5-APS diagnosis vs. hospitalized adolescents without a DSM-5-APS diagnosis.

Methods: Interviewing help-seeking, hospitalized adolescents (aged 12-18 years) and their caregivers independently with established research instruments, we (1) evaluated the presence of APS among non-psychotic adolescents, (2) characterized and compared APS and non-APS individuals regarding sociodemographic, illness and intervention characteristics, (3) correlated psychopathology with levels of functioning and severity of illness and (4) investigated the influence of individual clinical, functional and comorbidity variables on the likelihood of participants to be diagnosed with APS.

Results: Among 248 consecutively recruited adolescents (age=15.4 \pm 1.5 years, females $=69.6 \%)$ with non-psychotic psychiatric disorders, 65 (26.2\%) fulfilled APS criteria and 183 (73.8\%) did not fulfill them. Adolescents with APS had higher number 
of psychiatric disorders than non-APS adolescents (3.5 vs. 2.4, $p<0.001$; Cohen's $d=0.77$ ), particularly, disruptive behavior disorders (Cramer's $V=0.16$ ), personality disorder traits (Cramer's $\vee=0.26$ ), anxiety disorders (Cramer's $V=0.15)$, and eating disorders (Cramer's $V=0.16)$. Adolescents with APS scored higher on positive (Cohen's $d=1.5$ ), negative (Cohen's $d=0.55)$, disorganized (Cohen's $d=0.51$ ), and general symptoms (Cohen's $d=0.84$ ), and were more severely ill (Cohen's $d=1.0$ ) and functionally impaired (Cohen's $d=0.31$ ). Negative symptoms were associated with lower functional levels (Pearson $\rho=-0.17$ to $-0.20 ; p=0.014$ to 0.031). Global illness severity was associated with higher positive, negative, and general symptoms (Pearson $\rho=0.22$ to $0.46 ; p=0.04$ to $p<0.001)$. APS status was independently associated with perceptual abnormalities (OR $=2.0 ; 95 \% \mathrm{Cl}=1.6-2.5, p<0.001)$, number of psychiatric diagnoses $(\mathrm{OR}=1.5 ; 95 \% \mathrm{Cl}=1.2-2.0, p=0.002)$, and impaired stress tolerance $(\mathrm{OR}=1.4 ; 95 \% \mathrm{Cl}=1.1-1.7, p=0.002)\left(r^{2}=0.315, p<0.001\right)$.

Conclusions: A considerable number of adolescents hospitalized with non-psychotic psychiatric disorders meet DSM-5-APS criteria. These help-seeking adolescents have more comorbid disorders and more severe symptoms, functional impairment, and severity of illness than non-APS adolescents. Thus, they warrant high intensity clinical care.

Keywords: Attenuated Psychosis Syndrome (APS), adolescence, epidemiology, risk, psychosis, prevention

\section{INTRODUCTION}

Psychotic disorders, such as schizophrenia, are usually preceded by a clinical high-risk for psychosis (CHR-P) state (1), which is characterized by subtle symptoms, functional impairment and help-seeking behavior (2-4), as well as non-psychotic comorbidity $(5,6)$. The CHR-P state, which includes individuals at ultra-high risk for psychosis and/or those with basic symptoms, has allowed preventive efforts to be implemented $(7,8)$. This area of clinical research has grown until it has become one of the most established preventive approaches in psychiatry $(7,8)$.

The achievements and challenges of the CHR-P paradigm have been recently appraised by an umbrella review (9). In brief, three CHR-P subgroups have been established: attenuated psychotic symptoms; brief limited and intermittent psychotic symptoms (BLIPS) and genetic risk and deterioration (GRD) syndrome $(9,10)$. There are substantial diagnostic (11), prognostic $(10,12)$, clinical (13), and therapeutic (14) differences across these three subgroups. For example, psychosis risk is higher in the BLIPS group (38\%) than in the attenuated psychotic symptoms group (24\%) and higher in both groups than in the GRD group (8\%) at $>48$ months follow-up (10).

Although most research and clinical studies have evaluated the three groups together (15-17), the most common group by far is the attenuated psychotic symptoms group, which includes $85 \%$ of CHR-P individuals (10). Psychosis-risk syndromes, including attenuated psychotic symptoms, are usually characterized using semi-structured interviews as the Structured Interview for Psychosis-Risk Syndromes (SIPS) $(18,19)$ or the Comprehensive Assessment of At-Risk Mental States (CAARMS) (1), which have comparable prognostic accuracy (20). In the SIPS, the characterization used is Attenuated Positive Symptoms Syndrome (APSS). Seven years ago, the DSM-5 introduced the Attenuated Psychosis Syndrome (APS) diagnosis in the research appendix, listed in both section II and section III (21) (Figure 1). This diagnosis is defined by the presence of delusions, hallucinations, or disorganized speech in attenuated form, but with sufficient severity and frequency to warrant clinical attention $(23,24)$ (Figure 1). The diagnostic, prognostic, and therapeutic characteristics of this diagnosis have been recently appraised by a systematic review and meta-analysis (21). This review concluded that DSM-5-APS criteria have received substantial concurrent and prognostic validation, mostly driven by research in adult populations (21). A previous study looking at the agreement between CAARMS and DSM-5-APS criteria found that the agreement was only moderate (kappa 0.59) (25). Meanwhile, as findings from other studies point out $(26,27)$, SIPS and DSM criteria for APS are more similar (Figure 1).

While most reports to date on APS are based on cohorts that also include adults $(25,28-30)$, APS features often occur for the first time in adolescence $(31,32)$. Broadly speaking, studies that focus on DSM-5-APS in adolescents are scarce $(21,22)$, and there are few studies on APS in adolescents in clinical care and hospital settings.

To our knowledge, only a few efforts have been made (22, 33, 34) to characterize APS, excluding other ultra-high risk criteria, and advance knowledge specifically in children and adolescents, comparing them to other help-seeking individuals. Among them, 22 APS individuals were compared to other treatment-seeking individuals and healthy controls regarding clinical and cognitive features (34), finding that APS was associated with impaired 


\begin{tabular}{|c|c|c|c|}
\hline Criteria & $\begin{array}{c}\text { DSM-5-APS Section III } \\
\text { (American Psychiatric Association, 2013) }\end{array}$ & $\begin{array}{c}\text { DSM-5-APS Section II } \\
\text { (American Psychiatric Association, 2013) }\end{array}$ & $\begin{array}{c}\text { APSS SIPS } \\
\text { (Miller et al., 1999;Miller et al., } \\
\text { 2003;McGlashan T, 2010) }\end{array}$ \\
\hline Severity & $\begin{array}{l}\text { A. At least one of the following symptoms is } \\
\text { present in attenuated form, with relatively } \\
\text { intact reality testing, and is of sufficient } \\
\text { severity or frequency to warrant clinical } \\
\text { attention: } \\
\text { 1. Delusions } \\
\text { 2. Hallucinations } \\
\text { 3. Disorganized speech }\end{array}$ & $\begin{array}{l}\text { Examples of presentations that can be } \\
\text { specified using this designation include APS. } \\
\text { This syndrome is defined } \\
\text { by psychotic-like symptoms below a } \\
\text { threshold for full psychosis (e.g., they are } \\
\text { less severe and more transient, and insight is } \\
\text { relatively maintained) }\end{array}$ & $\begin{array}{l}\text { SOPS-positive symptom scales P1. unusual } \\
\text { thought content, P2. suspiciousness, P3. } \\
\text { grandiose ideas, P4. perceptual abnormalities, } \\
\text { P5. disorganized communication, with at least } \\
\text { one of these symptoms rated } 3,4 \text {, or } 5 \\
\text { indicating clinically significant disturbance } \\
\text { below a psychotic level of intensity }\end{array}$ \\
\hline Frequency & $\begin{array}{l}\text { B. Symptom(s) must have been present at } \\
\text { least once per week for the past month }\end{array}$ & Not specified & $\begin{array}{l}\text { Symptoms ever been present at an average } \\
\text { frequency of at least once/week over a month }\end{array}$ \\
\hline $\begin{array}{r}\text { New onset and } \\
\text { worsening }\end{array}$ & $\begin{array}{l}\text { C. Symptom(s) must have begun or } \\
\text { worsened in the past year }\end{array}$ & Not specified & $\begin{array}{l}\text { Begin within the past year, or any currently } \\
\text { rate one or more scale points higher compared } \\
\text { to } 12 \text { months ago; rated only symptoms that } \\
\text { occurred over the past month }\end{array}$ \\
\hline Distress/disability & $\begin{array}{l}\text { D. Symptom(s) is sufficiently distressing and } \\
\text { disabling to the individual to warrant clinical } \\
\text { attention }\end{array}$ & $\begin{array}{l}\text { Symptoms cause clinically significant } \\
\text { distress or impairment in social, } \\
\text { occupational, or other important areas of } \\
\text { functioning. }\end{array}$ & $\begin{array}{l}\text { Attenuated positive symptoms sufficiently } \\
\text { distressing and disabling to the patient to } \\
\text { warrant clinical attention }\end{array}$ \\
\hline $\begin{array}{r}\text { Differential } \\
\text { diagnosis }\end{array}$ & $\begin{array}{l}\text { E. Symptom(s) is not better explained by } \\
\text { another mental disorder, including a } \\
\text { depressive or bipolar disorder with psychotic } \\
\text { features, and is not attributable to the } \\
\text { physiological effects of a substance or } \\
\text { another medical condition }\end{array}$ & $\begin{array}{l}\text { Symptoms do not meet the full criteria for } \\
\text { any of the disorders in the schizophrenia } \\
\text { spectrum and other psychotic disorders } \\
\text { diagnostic class }\end{array}$ & $\begin{array}{l}\text { Symptoms ever not been explained better by } \\
\text { another DSM disorder }\end{array}$ \\
\hline
\end{tabular}

FIGURE 1 | DSM-5-APS Attenuated Psychosis Syndrome diagnostic criteria compared with SIPS operationalization [adapted from (Gerstenberg et al. (22); Salazar De Pablo et al. (21)]. APS, Attenuated Psychosis Syndrome; APSS, Attenuated Positive Symptoms Syndrome; SIPS, Structured Interview for Psychosis-Risk Syndromes.

neurocognition. Also, APS was associated with self-reported internalizing problems and thought problems in a study with 7 APS adolescents (33). One further study without a comparison group found that an older age of APS presentation in adolescents (comparing 9-14 years vs. 15-18 years) was associated with better social and role functioning and fewer depressive symptoms (35).

There is little evidence on how many help-seeking adolescents accessing inpatient care meet APS criteria. Our preliminary data from the Adolescent Mood Disorder and Psychosis Study (AMDPS) clinical study compared the first 21 APS and 68 non-APS adolescents who were recruited and found that APS was present in $23.6 \%$ of psychiatrically hospitalized adolescents, who suffered from a broad range of psychiatric symptoms and disorders (22).

Although specific knowledge for APS is limited, CHR-P individuals show impairments in work, educational and social functioning as well as poor quality of life $(9,36)$. Furthermore, psychopathology can adversely influence functioning (37). Negative symptoms have been associated with functioning, both daily (38), work related (39) and real-world functioning (40). Among CHR-P individuals, the severity of attenuated positive and negative symptoms has been associated with some outcomes [e.g., transition to psychosis $(9,21)]$ but not with others [e.g., cannabis use (9)]. Our preliminary results showed that poorer functioning in adolescents with APS was associated with more severe attenuated positive, negative, and general symptoms (22).

In the CHR-P field, the influence of sociodemographic and clinical variables on diagnostic and treatment outcomes has been widely studied, particularly regarding the transition to psychosis (41-45). Unusual thought content and suspiciousness have been found to predict conversion to psychosis along with decline in social functioning, lower verbal learning and memory performance (46). However, there is no convincing evidence of the association between any variable and the onset of psychotic disorders according to a meta-analysis, and only attenuated positive psychotic symptoms and global functioning show suggestive evidence (47). The influence of demographic and clinical variables on the presence of APS, particularly in adolescents, is even less known. In the first 89 individuals recruited into AMDPS, lowest GAF score in the past year, and social isolation were independently associated with APS (22).

The current study analyzes the final sample of this cohort of hospitalized adolescents to (1) assess how many nonpsychotic, help-seeking adolescents accessing inpatient care meet APS criteria, (2) describe and compare both groups regarding sociodemographic, illness and intervention characteristics, (3) correlate attenuated positive, negative, general and disorganized symptoms with the level of functioning and severity of illness, and (4) investigate the influence of individual clinical, functional and comorbidity variables, selected empirically, on the likelihood of participants to be diagnosed with APS.

Based on prior literature, we hypothesized that (1) a significant number of adolescents with non-psychotic psychiatric disorders would fulfill APS criteria, (2) APS individuals would report significant comorbidity, clinical burden and functional impairment that would exceed those of non-APS individuals, (3) severity of negative symptoms would be significantly associated with the level of functioning and severity of illness, and (4) 
APS status would be associated with specific attenuated positive symptoms and other clinical variables.

\section{MATERIALS AND METHODS}

\section{Design and Setting}

AMDPS was registered at ClinicalTrials.gov (NCT01383915).

Participants were recruited consecutively into AMDPS between September 2009 and July 2017 from the Adolescent Child and Adolescent Inpatient Unit of The Zucker Hillside Hospital, New York, USA $(48,49)$. AMDPS is an ongoing, prospective study that aims to assess predictors of the development of bipolar disorder and psychotic disorders in hospitalized adolescents. Analyses for this study are restricted to baseline data. The protocol was approved by the Institutional Review Board of the North Shore-Long Island Jewish Health System in accordance with the Helsinki Declaration of 1975 and the UNESCO Universal Declaration on human rights. Written informed consent was obtained from subjects aged 18 or the guardians/legal representatives of minors, obtaining written assent from the minors.

\section{Participants}

Inclusion criteria for AMDPS study were: (1) age 12-18 years; (2) hospitalized at the adolescent inpatient unit of The Zucker Hillside Hospital, a self-standing psychiatric hospital; (3) admission chart diagnosis of any bipolar-spectrum disorder, cyclothymia, major depressive disorder, depressive disorder not otherwise specified (NOS), dysthymia or mood disorder NOS, schizophrenia, schizoaffective disorder, schizophreniform disorder or psychotic disorder NOS, re-evaluated by research interview, using the Structured Clinical Interview for DSM Disorders (SCID) (50), supplemented for missing pediatric diagnoses by the Schedule for Affective Disorders and Schizophrenia for School-Age Children-Present and Lifetime version (K-SADS-PL) (51); (4) subject and guardian/caregiver (if subject $<18$ ) willing and able to provide written, informed consent/assent. Exclusion criteria were: (1) an estimated premorbid IQ $<70$; (2) DSM-5 clinical criteria for autism spectrum disorders or pervasive developmental disorder and (3) history of any neurological or medical condition known to affect the brain.

For the purpose of this study, we also excluded patients: (1) with a psychotic disorder according to DSM-5 criteria; (2) in whom the Structured Interview for Psychosis-Risk Syndromes, version 4.0 (52) was not completed (Figure 2).

Psychiatric diagnoses were established in diagnostic research consensus conferences based on in-person independent interview assessments of the adolescents and caregivers whenever possible. The interviews were typically conducted a few days after hospital admission. In consensus conferences, both assessments were integrated assuming that symptoms are more likely forgotten or hidden than invented or exaggerated. Also, SIPS items were discussed one by one for both interviews to reach to the correct value, and every psychiatric primary or comorbid diagnosis, including APS, was discussed among all the attendees and confirmed by the study lead (CUC). In order to conduct AMDPS assessments, experienced clinicians had to be certified by the study PI (CUC) after having gone through a structured training program, which involved observing several assessments, followed by conducting several assessments in front of one of the certified trainers, and presenting their ratings as part of a diagnostic consensus conference led by the study PI. All raters continually took part in the diagnostic consensus conference, during which all interview ratings were discussed and finalized as part of a group consensus, which served to assure validity of the ratings, facilitate interrater reliability via consensual rating, and avoid rater drift after completion of the initial training and certification.

\section{Diagnostic Assessments}

The Structured Interview for Psychosis-Risk Syndromes (SIPS) $(18,19)$ is a semi-structured interview used to diagnose psychosis-risk syndromes in the last month. We used SIPS Version 4.0 (53). It includes four primary sections according to the symptoms evaluated: attenuated positive symptoms, negative symptoms, disorganized symptoms, and general symptoms. As part of the SIPS, the Scale of Prodromal Symptoms (SOPS) is used to determine whether participants meet research criteria for APSS. SIPS/SOPS psychometric instruments and DSM-5 criteria were both used to diagnose DSM-5-APS in a precise way.

\section{Clinical and Functional Assessments}

Additional rating scales were administered to both adolescents and their caregivers, including the Clinical Global ImpressionSeverity scale (CGI-S; range $=1-7$ ) to assess the overall severity of illness (54) and Global Assessment of Functioning (GAF) scale (55) to assess global functioning. Social and role functioning were assessed as well, using the Global Functioning: Social (GF: Social) and the Global Functioning: Role (GF: Role) $(56,57)$ scales. Insight was assessed using the Scale to Assess Unawareness of Mental Disorder (SUMD) (58), using three general awareness items: mental disorder, social consequences of mental disorder, and achieved effect of medication. Suicidality was assessed as the $\%$ of individuals who reported suicidal ideation lifetime and those with a history of at least one suicide attempt prior to admission.

\section{Data Analysis}

We used descriptive statistics to characterize the study population, including diagnosis according to DSM-5 criteria, demographic variables, clinical characteristics and treatment characteristics. Between-group comparisons of categorical variables were performed using $\chi^{2}$-test or Fisher's exact test, whenever at least one cell contained $\leq 5$ patients. For comparisons of continuous variables, we used $t$-test. The following effect sizes were calculated: (a) Cramer's V for $\chi^{2}$ (59), which was interpreted as follows: $0.1=$ small; $0.3=$ moderate; $0.5=$ large effect size; and (b) Cohen's d (60) for $t$-test, which was interpreted as follows: $0.2=$ small; $0.5=$ moderate; $0.8=$ large effect size, using effect size calculator for $t$-test (61). We correlated attenuated positive, negative, general and disorganized symptoms with the level of functioning and severity of illness using Pearson's correlation. We finally conducted a multivariable, backward logistic regression analysis, entering into the model 


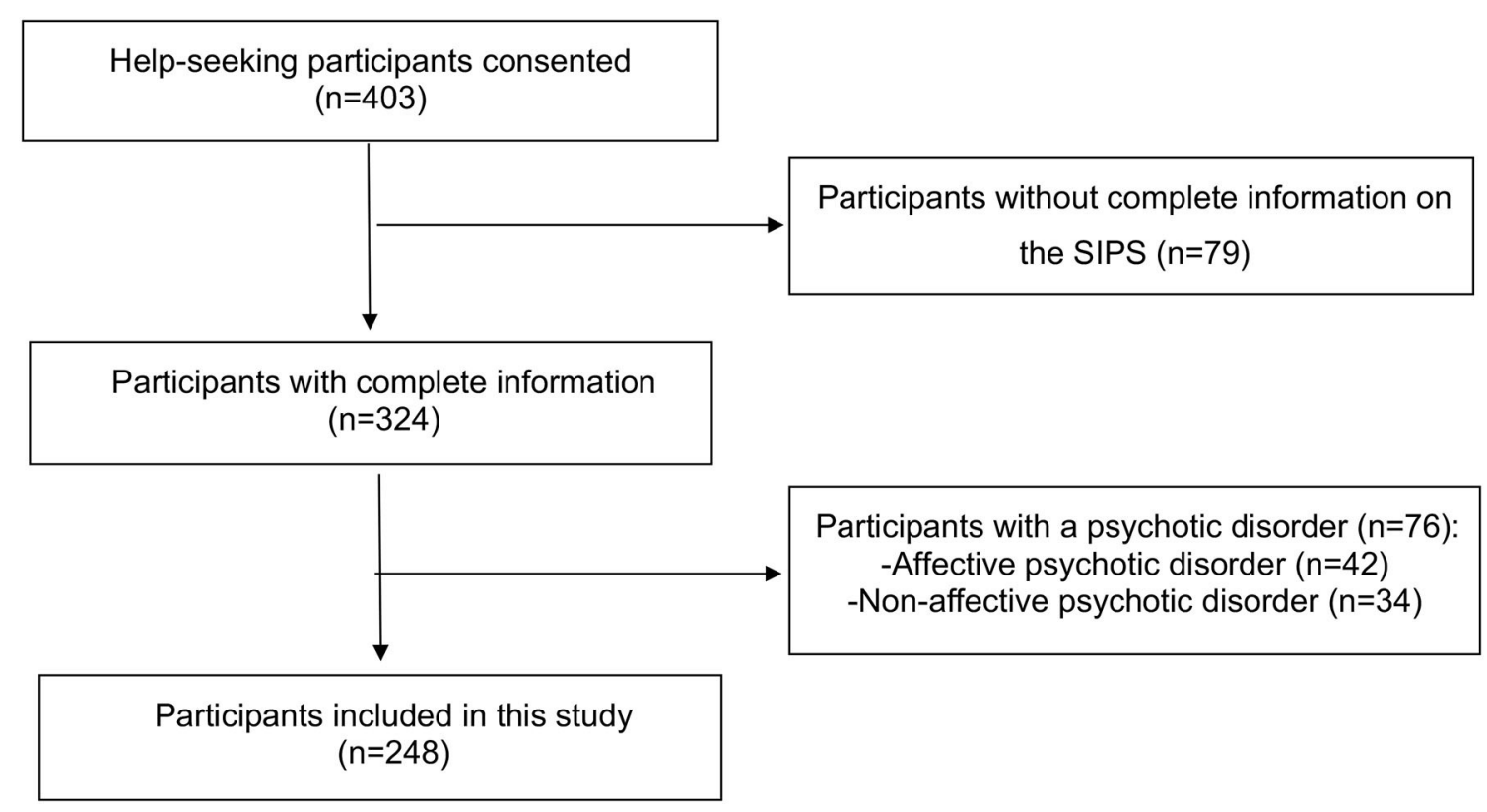

FIGURE 2 | Flowchart outlining selection of study population. SIPS, Structured Interview for Psychosis-Risk Syndromes.

variables that were significantly different $(p<0.05)$ between APS vs. non-APS groups in univariate analyses with data in $>67 \%$ of subjects. For DSM-5 diagnoses, we entered into the multivariable model broad diagnostic categories (e.g., anxiety disorders), instead of single diagnoses (e.g., panic disorder), that were significantly different between the APS and non-APS group, in order to maximize power for the analyses. For the SIPS psychopathology symptoms, we included only individual items and not subscale sum scores to identify potentially clinically relevant symptoms that can guide clinical identification of APS status. The percent variance explained by the significant variables retained in the final multivariable logistic regression model was expressed as $r^{2}$. Significance level was set at alpha $=0.05$, and all tests were two-tailed. Statistical analyses were performed with SPSS 21 for Windows software (IBM) (62).

\section{RESULTS}

\section{Demographic, Comorbidity and Treatment Characteristics}

Altogether, 403 help-seeking adolescents and their guardians/legal representatives were consented into AMDPS. Of those, $79(16.9 \%)$ were excluded from this study due to incomplete information on the SIPS, and of the remaining 324 patients, $76(23.5 \%)$ had a psychotic disorder and were therefore also excluded. Finally, 248 hospitalized adolescents with non-psychotic psychiatric disorders were included in this study. Of those, 65 (26.2\%) fulfilled DSM-5-APS criteria and 183 (83.8\%) did not fulfill APS criteria (Figure 2). Agreement was $100 \%$ between DSM- 5 clinical criteria and the SIPS.
Table 1 shows the demographic, illness and baseline treatment characteristics of the sample at the time of the interview. The average age of participants was 15.4 years $(\mathrm{SD}=1.5)$. Most participants were female (69.4\%) and white (54.6\%). There were no significant differences between the two groups in any of the demographic characteristics (Table 1).

APS individuals had a higher number of comorbid disorders (3.5 vs. 2.4, $p<0.001$; Cohen's $\mathrm{d}=0.77$ ) compared to non-APS individuals. The most frequent in the total sample (APS plus non-APS) were depressive disorders (77.0\%), particularly major depressive disorder (55.2\%), followed by anxiety disorders (42.7\%), and disruptive behavior disorders (39.1\%). The following disorders were significantly more common in individuals with APS vs. non-APS: disruptive behavior disorders ( $p=0.011$; Cramer's $\mathrm{V}=0.16)$, including oppositional defiant disorder $(p=0.03$; Cramer's $\mathrm{V}=0.14)$, and conduct disorder ( $p=0.049$; Cramer's $\mathrm{V}=0.12)$; bipolar disorders $(p=0.002$, Cramer's $\mathrm{V}=0.20)$, including other specified bipolar and related disorders $(p=0.005$; Cramer's $\mathrm{V}=0.18$ - -also known as bipolar disorder NOS as defined by the COBY study criteria (63)-; personality disorder traits ( $p<0.001$; Cramer's $\mathrm{V}=0.26$ ), including borderline personality disorder traits $(p=0.002$; Cramer's $\mathrm{V}=0.20)$ and other personality disorder traits $(p<0.001$; Cramer's $\mathrm{V}=0.27)$; anxiety disorders $(p=0.016$; Cramer's $V=0.15)$, including panic disorder ( $p=0.031$; Cramer's $\mathrm{V}=0.14)$, generalized anxiety disorder $(p=0.011$; Cramer's $\mathrm{V}=0.16)$ and specific phobia ( $p=0.005$; Cramer's $\mathrm{V}=0.18$ ); and eating disorders $(p=0.012$; Cramer's $\mathrm{V}=0.16)$. The two groups did not differ in comorbid depressive disorders, substance use 
TABLE 1 | Demographic, comorbidity and treatment characteristics.

\begin{tabular}{|c|c|c|c|c|c|}
\hline & $\begin{array}{c}\text { Total } \\
(n=248)\end{array}$ & $\begin{array}{c}\text { APS } \\
(n=65)\end{array}$ & $\begin{array}{l}\text { Non-APS } \\
(n=183)\end{array}$ & $P$-value & Effect size \\
\hline \multicolumn{6}{|l|}{ Demographic characteristics } \\
\hline Sex, male, $n(\%)$ & 76 (30.6) & $16(24.6)$ & $60(32.8)$ & 0.22 & 0.078 \\
\hline Age (years) mean \pm SD & $15.4 \pm 1.5$ & $15.5 \pm 1.3$ & $15.4 \pm 1.5$ & 0.63 & 0.070 \\
\hline Race/ethnicity, $n,(\%)^{\mathrm{a}}$ & & & & 0.60 & 0.11 \\
\hline White & $124(54.6)$ & $32(55.2)$ & $92(54.4)$ & & \\
\hline Black or African American & $41(18.1)$ & $13(22.4)$ & $28(16.6)$ & & \\
\hline Other & $31(13.7)$ & $8(13.8)$ & $23(13.6)$ & & \\
\hline Asian or Pacific Islander & $28(12.3)$ & $5(8.6)$ & $23(13.6)$ & & \\
\hline Indian American & $3(1.3)$ & $0(0.0)$ & $3(1.8)$ & & \\
\hline Estimated IQ, mean $\pm \mathrm{SD}$ & $108.4 \pm 18.9$ & $107.2 \pm 17.8$ & $108.8 \pm 19.3$ & 0.56 & 0.088 \\
\hline \multicolumn{6}{|l|}{ Lifetime consensus diagnoses, $n$ (\%) } \\
\hline Number of psychiatric diagnoses & $2.6 \pm 1.5$ & $3.5 \pm 1.5$ & $2.4 \pm 1.4$ & $<0.001$ & 0.77 \\
\hline Depressive disorders & $191(77.0)$ & $52(80.0)$ & $139(76.0)$ & 0.51 & 0.042 \\
\hline Major depressive disorder & $137(55.2)$ & $42(64.6)$ & 95 (51.9) & 0.077 & 0.11 \\
\hline Other specified depressive disorder & $53(21.4)$ & $10(15.4)$ & $43(23.5)$ & 0.170 & 0.087 \\
\hline Persistent depressive disorder & $18(7.3)$ & $5(7.7)$ & $13(7.1)$ & 0.87 & 0.010 \\
\hline Disruptive, impulse-control and conduct disorders & $97(39.1)$ & $34(52.3)$ & $63(34.4)$ & 0.011 & 0.16 \\
\hline Attention-deficit/hyperactivity disorder & $58(23.4)$ & $13(20.0)$ & $45(24.6)$ & 0.45 & 0.048 \\
\hline Oppositional defiant disorder & $40(16.1)$ & $16(24.6)$ & $24(13.1)$ & 0.03 & 0.14 \\
\hline Conduct disorder & $26(10.5)$ & $11(16.9)$ & $15(8.2)$ & 0.049 & 0.12 \\
\hline Disruptive behavior disorder not otherwise specified & $11(4.4)$ & $4(6.2)$ & $7(3.8)$ & 0.43 & 0.050 \\
\hline Bipolar disorders & $57(23.0)$ & $24(36.9)$ & $33(18.0)$ & 0.002 & 0.20 \\
\hline Other specified bipolar and related disorder & $41(16.5)$ & $18(27.7)$ & 23 (12.6) & 0.005 & 0.18 \\
\hline Bipolar I disorder & $12(4.8)$ & $6(9.2)$ & $6(3.3)$ & 0.055 & 0.12 \\
\hline Bipolar II disorder & $8(3.2)$ & $3(4.6)$ & $5(2.7)$ & 0.46 & 0.047 \\
\hline Personality disorder traits & $48(19.4)$ & $24(36.9)$ & $24(13.1)$ & $<0.001$ & 0.26 \\
\hline Borderline personality disorder traits & $42(16.9)$ & $19(29.2)$ & $23(12.6)$ & 0.002 & 0.20 \\
\hline Other personality disorder traits & $13(5.2)$ & $10(15.4)$ & $3(1.6)$ & $<0.001$ & 0.27 \\
\hline Substance use disorders & $39(15.7)$ & $13(20.0)$ & $26(14.2)$ & 0.27 & 0.070 \\
\hline Cannabis use disorder & $31(12.5)$ & $9(13.8)$ & $22(12.0)$ & 0.70 & 0.024 \\
\hline Alcohol use disorder & $14(5.6)$ & $6(9.2)$ & $8(4.4)$ & 0.14 & 0.093 \\
\hline Others & $6(2.4)$ & $2(3.1)$ & $4(2.2)$ & 0.67 & 0.026 \\
\hline Trauma- and stressor-related disorders & $38(15.3)$ & $8(12.3)$ & $30(16.4)$ & 0.43 & 0.050 \\
\hline Posttraumatic stress disorder & $20(8.1)$ & $7(10.8)$ & $13(7.1)$ & 0.35 & 0.059 \\
\hline Adjustment disorder & $19(7.7)$ & $2(3.1)$ & $17(9.3)$ & 0.11 & 0.10 \\
\hline Anxiety disorders & $106(42.7)$ & $36(55.4)$ & $70(38.3)$ & 0.016 & 0.15 \\
\hline Panic disorder & $63(25.4)$ & $23(35.4)$ & $40(21.9)$ & 0.031 & 0.14 \\
\hline Generalized anxiety disorder & $37(14.9)$ & $16(24.6)$ & $21(11.5)$ & 0.011 & 0.16 \\
\hline Social phobia & $24(9.7)$ & $10(15.4)$ & $14(7.7)$ & 0.07 & 0.11 \\
\hline Others & $20(8.1)$ & $5(7.7)$ & $15(8.2)$ & 0.90 & 0.008 \\
\hline Obsessive-compulsive disorder & $13(5.2)$ & $6(9.2)$ & $7(3.8)$ & 0.093 & 0.11 \\
\hline Specific phobia & $9(3.6)$ & $6(9.2)$ & $3(1.6)$ & 0.005 & 0.18 \\
\hline \multicolumn{6}{|l|}{ Other diagnostic categories } \\
\hline Eating disorders & $20(8.1)$ & $10(15.4)$ & $10(5.5)$ & 0.012 & 0.16 \\
\hline Enuresis (not due to a general medical condition) & $9(3.6)$ & $3(4.6)$ & $6(3.3)$ & 0.62 & 0.031 \\
\hline \multicolumn{6}{|l|}{ Treatment characteristics at time of the interview $n(\%)^{b}$} \\
\hline Antipsychotics ${ }^{c}$ & $118(53.6)$ & $37(66.1)$ & $81(49.4)$ & 0.031 & 0.15 \\
\hline Antidepressants ${ }^{d}$ & $112(50.9)$ & $24(42.9)$ & $88(53.7)$ & 0.16 & 0.094 \\
\hline Mood stabilizers ${ }^{e}$ & $55(25.0)$ & $14(25.0)$ & $41(25.0)$ & 1.0 & 0.000 \\
\hline
\end{tabular}


TABLE 1 | Continued

\begin{tabular}{|c|c|c|c|c|c|}
\hline & $\begin{array}{c}\text { Total } \\
(n=248)\end{array}$ & $\begin{array}{c}\text { APS } \\
(n=65)\end{array}$ & $\begin{array}{l}\text { Non-APS } \\
(n=183)\end{array}$ & $P$-value & Effect size \\
\hline Lithium & 41 (18.6) & $9(16.1)$ & 32 (19.5) & 0.57 & 0.038 \\
\hline Anxiolytics ${ }^{f}$ & 23 (10.5) & 7 (12.5) & $16(9.8)$ & 0.56 & 0.039 \\
\hline Others $^{\text {h }}$ & $21(9.5)$ & 7 (12.5) & $14(8.5)$ & 0.38 & 0.059 \\
\hline Antiepileptic drugs & $18(8.2)$ & $6(10.7)$ & $12(7.3)$ & 0.42 & 0.054 \\
\hline ADHD medication ${ }^{9}$ & $4(1.8)$ & $0(0.0)$ & $4(2.4)$ & 0.24 & 0.080 \\
\hline Two or more drugs & $91(41.4)$ & $22(39.3)$ & $69(42.1)$ & 0.71 & 0.025 \\
\hline Three or more drugs & $25(11.4)$ & 7 (12.5) & $18(11.0)$ & 0.76 & 0.021 \\
\hline
\end{tabular}

$A D H D$, Attention Deficit Hyperactivity Disorder; APS, Attenuated Psychosis Syndrome.

a Information available for 227 individuals.

${ }^{b}$ Information available for 220 individuals.

${ }^{c}$ Antipsychotics: aripiprazole, molindone, quetiapine, risperidone, lurasidone, ziprasidone, olanzapine, haloperidol, chlorpromazine, clozapine.

${ }^{d}$ Antidepressants: amitriptyline, nortriptyline, bupropion, citalopram, escitalopram, duloxetine, fluoxetine, paroxetine, sertraline, venlafaxine, mirtazapine.

${ }^{e}$ Mood stabilizers: lamotrigine, lithium, valproic acid.

${ }^{f}$ Anxiolytics/tranquilizers: clonazepam, lorazepam, hydroxyzine, buspirone.

${ }^{g}$ Anti-ADHD medications: atomoxetine, lisdexamphetamine, methylphenidate, modafinil, clonidine, guanfacine.

hOthers: zolpidem, melatonin, propranolol, diphenhydramine, amlodipine.

Bold values indicate $p<0.05$ for between-groups analysis.

disorders, trauma and stressor-related disorders or enuresis (all $p>0.05$ ).

Overall, the most used psychotropic medications at the time of the interview were antipsychotics $(53.6 \% ; p=0.031)$, followed by antidepressants (50.9\%; $p=0.16)$, and mood stabilizers $(25.0 \% ; p=1.0)$. Antipsychotics, which were more common in the APS group $(p=0.031$; Cramer's $\mathrm{V}=0.15)$, were the only medication class that was significantly different between the groups. The use of multiple medications (use of two or more drugs or use of three or more drugs) was equally frequent in both groups ( $p=0.71$ to 0.76$)$.

\section{Severity of Symptoms and Symptom Domains}

Total attenuated positive $(p<0.001$; Cohen's $d=1.5)$, negative $(p<0.001$; Cohen's $\mathrm{d}=0.55)$, disorganized $(p<0.001$; Cohen's $\mathrm{d}=0.51)$, and general $(p<0.001$; Cohen's $\mathrm{d}=0.84)$ symptom scores were significantly higher in APS individuals vs. non-APS hospitalized adolescents. All group-defining SIPS attenuated positive symptoms (unusual thought content, suspiciousness, grandiosity, perceptual abnormalities and disorganized communication) were significantly more severe in the APS group (Cohen's $d=0.39$ to 1.3 ), with the largest effect size for perceptual abnormalities (Cohen's $d=1.3$ ) (Table 2). Additionally, the following symptoms were more severe in the APS vs. non-APS group: social anhedonia ( $p<0.001$; Cohen's $\mathrm{d}=0.57)$, avolition $(p=0.002$; Cohen's $\mathrm{d}=0.51)$, experiences of emotions and self $(p<0.001$; Cohen's $d=0.54)$, bizarre thinking $(p<0.001$; Cohen's $d=0.60)$, trouble with focus and attention $(p=0.001$; Cohen's $\mathrm{d}=0.53)$, sleep disturbances $(p=0.002$; Cohen's $\mathrm{d}=0.38)$, dysphoric mood $(p=0.004$; Cohen's $d=0.34)$ and impaired stress tolerance $(p<0.001$; Cohen's $\mathrm{d}=0.63$ ).

\section{IIIness Severity, Functional Level, Illness Insight and Suicidality}

Overall illness severity (CGI-S) was higher in the APS group $(\mathrm{p}<0.001)$ and the effect size was large (Cohen's $\mathrm{d}=1.0)$. The mean current GAF score was $23.0 \pm 11.9$ in the APS group and $28.1 \pm 17.9$ in the non-APS group ( $p=0.012$; Cohen's $\mathrm{d}=0.31)$. Scores for the highest functioning in the past year ( $p=0.002$; Cohen's $\mathrm{d}=0.52)$ and lowest functioning in the past year $(p=0.002$; Cohen's $d=0.38)$ were lower in the APS group as well (i.e., poorer functioning in the APS group). Unlike current role functioning, which did not differ significantly between the groups $(p=0.35)$, current social functioning was better in the non-APS group $(p=0.003 ; \mathrm{d}=0.66)$. Both groups did not differ regarding awareness of mental disorder or social consequences, suicidal ideation or suicidal attempts (all $p>0.05)$ (Table 3$)$.

\section{Correlation Between Symptom Domains and Functioning (GAF)-Severity of Illness (CGI-S)}

Total negative symptoms were significantly correlated with lower current functioning (Pearson $\rho=-0.17 ; p=0.031$ ), lower lowest functioning in the past year (Pearson $\rho=-0.20 ; p=0.014$ ) and lower highest functioning reached in the past year (Pearson $\rho=-0.19 ; p=0.022$ ). Functioning was not significantly correlated with attenuated positive symptoms, disorganized symptoms or general symptoms. The severity of illness was associated with more severe SIPS positive, negative, disorganized and general symptoms (Pearson $\rho=0.22$ to $0.46 ; p=0.04$ to $p<0.001$ ) (Table 4).

\section{Multivariable Logistic Regression Analysis}

Independent correlates of APS in the final model were perceptual abnormalities $(\mathrm{OR}=2.0 ; 95 \% \mathrm{CI}=1.6-2.5, p<0.001)$, number of psychiatric diagnoses $(\mathrm{OR}=1.5 ; 95 \% \mathrm{CI}=1.2-2.0, p=0.002)$, 
TABLE 2 | Severity of structured interview of prodromal syndromes (SIPS) assessed symptoms and symptom domains.

\begin{tabular}{|c|c|c|c|c|c|}
\hline & $\begin{array}{c}\text { Total } \\
(n=248)\end{array}$ & $\begin{array}{c}\text { APS } \\
(n=65)\end{array}$ & $\begin{array}{l}\text { Non-APS } \\
(n=183)\end{array}$ & $P$-value & Effect size \\
\hline \multicolumn{6}{|c|}{ Structured interview of prodromal syndromes mean \pm SD } \\
\hline \multicolumn{6}{|l|}{ Positive symptoms } \\
\hline Total positive symptom score & $3.2 \pm 4.1$ & $7.4 \pm 4.6$ & $1.9 \pm 3.3$ & $<0.001$ & 1.5 \\
\hline Highest positive symptom score & $1.8 \pm 1.8$ & $3.5 \pm 1.3$ & $1.2 \pm 1.6$ & $<0.001$ & 1.5 \\
\hline P1 unusual thought content & $0.73 \pm 1.4$ & $1.6 \pm 1.6$ & $0.41 \pm 1.1$ & $<0.001$ & 0.95 \\
\hline P2 suspiciousness & $0.84 \pm 1.3$ & $1.8 \pm 1.6$ & $0.48 \pm 0.93$ & $<0.001$ & 1.2 \\
\hline P3 grandiosity & $0.54 \pm 1.2$ & $0.89 \pm 1.5$ & $0.41 \pm 1.1$ & 0.024 & 0.39 \\
\hline P4 perceptual abnormalities/hallucinations & $0.99 \pm 1.7$ & $2.3 \pm 1.9$ & $0.47 \pm 1.2$ & $<0.001$ & 1.3 \\
\hline P5 disorganized communication & $0.29 \pm 0.86$ & $0.63 \pm 1.1$ & $0.16 \pm 0.68$ & $<0.001$ & 0.58 \\
\hline \multicolumn{6}{|l|}{ Negative symptoms } \\
\hline Total negative symptom score & $8.0 \pm 6.22$ & $10.4 \pm 6.7$ & $7.1 \pm 5.8$ & $<0.001$ & 0.55 \\
\hline Highest negative symptom score & $3.4 \pm 1.83$ & $3.8 \pm 1.6$ & $3.2 \pm 1.9$ & 0.012 & 0.33 \\
\hline N1 social anhedonia & $1.5 \pm 1.79$ & $2.2 \pm 1.9$ & $1.2 \pm 1.7$ & $<0.001$ & 0.57 \\
\hline N2 avolition & $2.1 \pm 2.0$ & $2.9 \pm 1.7$ & $1.9 \pm 2.0$ & 0.002 & 0.51 \\
\hline N3 expression of emotions & $0.88 \pm 1.5$ & $1.2 \pm 1.6$ & $0.75 \pm 1.4$ & 0.061 & 0.31 \\
\hline N4 experience of emotions and self & $0.87 \pm 1.7$ & $1.6 \pm 2.3$ & $0.65 \pm 1.4$ & $<0.001$ & 0.54 \\
\hline N5 ideational richness & $0.20 \pm 0.65$ & $0.18 \pm 0.18$ & $0.21 \pm 0.75$ & 0.88 & 0.050 \\
\hline N6 occupational functioning & $2.4 \pm 2.1$ & $2.5 \pm 2.4$ & $2.3 \pm 2.0$ & 0.31 & 0.11 \\
\hline \multicolumn{6}{|l|}{ Disorganized symptoms } \\
\hline Total disorganized symptom score & $3.1 \pm 3.2$ & $4.3 \pm 3.7$ & $2.7 \pm 2.9$ & $<0.001$ & 0.51 \\
\hline Highest disorganized symptom score & $2.2 \pm 1.9$ & $2.9 \pm 1.7$ & $2.03 \pm 1.9$ & 0.003 & 0.47 \\
\hline D1 odd behavior or appearance & $0.16 \pm 0.94$ & $0.14 \pm 1.4$ & $0.17 \pm 0.71$ & 0.297 & -0.03 \\
\hline D2 bizarre thinking & $0.18 \pm 0.7$ & $0.48 \pm 1.1$ & $0.08 \pm 0.4$ & $<0.001$ & 0.60 \\
\hline D3 trouble with focus and attention & $1.9 \pm 1.8$ & $2.6 \pm 1.7$ & $1.66 \pm 1.81$ & 0.001 & 0.53 \\
\hline D4 impairment in personal hygiene & $0.76 \pm 1.7$ & $0.86 \pm 2.1$ & $0.73 \pm 1.54$ & 0.45 & 0.08 \\
\hline \multicolumn{6}{|l|}{ General symptoms } \\
\hline Total general symptom score & $8.4 \pm 4.5$ & $11.0 \pm 3.5$ & $7.5 \pm 4.4$ & $<0.001$ & 0.84 \\
\hline Highest general symptom score & $4.3 \pm 1.7$ & $5.0 \pm 1.1$ & $4.1 \pm 1.8$ & $<0.001$ & 0.55 \\
\hline G1 sleep disturbance & $2.3 \pm 1.9$ & $2.8 \pm 2.0$ & $2.1 \pm 1.8$ & 0.002 & 0.38 \\
\hline G2 dysphoric mood & $4.0 \pm 2.1$ & $4.5 \pm 2.3$ & $3.8 \pm 2.0$ & 0.004 & 0.34 \\
\hline G3 motor disturbance & $0.14 \pm 0.80$ & $0.17 \pm 1.4$ & $0.13 \pm 0.52$ & 0.73 & 0.05 \\
\hline G4 impaired stress tolerance & $1.9 \pm 2.1$ & $2.9 \pm 2.3$ & $1.6 \pm 1.9$ & $<0.001$ & 0.63 \\
\hline
\end{tabular}

Bold values indicate $p<0.05$ for between-groups analysis.

and impaired stress tolerance $(\mathrm{OR}=1.4 ; 95 \% \mathrm{CI}=1.1-1.7$, $p=0.002)$. The model including these three variables explained $31.5 \%$ of the variance $\left(r^{2}=0.315, p<0.001\right)$ (Table 5 ).

\section{DISCUSSION}

To our knowledge, this study is one of the very few and the largest to date to characterize and describe sociodemographic, illness and intervention characteristics in adolescents with APS vs. non-APS. Additionally, this study focused on help-seeking adolescents who had been admitted into an inpatient unit.

According to our results, $26.2 \%$ of the adolescents without a psychotic disorder diagnosis fulfilled APS criteria, a somewhat lower prevalence compared to a previous study including mostly adolescent outpatients $(33 \%)(64,65)$, but still a clinically significant and higher prevalence than the one found in nonhelp-seeking adolescents with disruptive behaviors (13\%) (33).
In the general population, a 7.2\% meta-analytical prevalence of psychotic experiences was estimated in children and adults (66). In the Philadelphia Neurodevelopmental Cohort study, 15.5\% of the 8-21 year old individuals reported significant psychotic symptoms and another $9.8 \%$ reported milder symptoms (67).

APS individuals had a higher number and distribution of comorbid conditions than non-APS individuals (Cohen's $\mathrm{d}=0.77$ ), particularly consisting of depressive disorders (5), anxiety disorders (5), and disruptive behavior disorders (68). This finding is clinically relevant because APS status has been associated with hospital treatment for mood and conduct disorders (33). Personality disorder traits, bipolar disorders, disruptive behavior disorders, eating disorders and anxiety disorders, were more frequent in the APS group than the non-APS group, although effect sizes were small. This result supports evidence of the association between APS $(21,22)$ as well as CHR-P $(9,69)$ with other comorbid mental disorders. 
TABLE 3 | Illness severity, functional level, illness insight and suicidality.

$\begin{array}{ccccc}\begin{array}{c}\text { Total } \\ (n=248)\end{array} & \text { APS } & \text { Non-APS } & \text { P-value } & \text { Effect size } \\ (n=65) & (n=183) & & \end{array}$

Characteristics

IIIness severity: clinical global impressions-severity scale (CGI-S) mean $\pm \mathrm{SD}^{\mathrm{a}}$

$\begin{array}{lr}\text { Overall severity of illness } & 4.2 \pm 1.03\end{array}$

Functional level: global assessment of functioning-scale (GAF) mean $\pm \mathrm{SD}^{\mathrm{b}}$

\section{Current GAF}

Highest GAF of past year

Lowest GAF of past year

Global functioning: role scale mean $\pm \mathrm{SD}^{\mathrm{c}}$

Current role functioning

Global functioning: social scale mean $\pm \mathrm{SD}^{\mathrm{c}}$

Current social functioning

Scale to assess unawareness of mental disorder mean $\pm S^{d}$

Awareness of mental disorder

Awareness of the effect of medication

Awareness of the social consequences

Suicidality, $n(\%)^{\mathrm{e}}$

Suicidal ideation

Suicide attempts

$26.8 \pm 16.7$
$57.7 \pm 14.7$
$23.1 \pm 15.0$

$$
5.9 \pm 1.8
$$

$6.5 \pm 1.7$

$2.2 \pm 1.7$

$2.1 \pm 1.5$

$1.9 \pm 1.5$

$131(61.8)$

21 (10.0)

\section{$4.8 \pm 0.94$}

$23.0 \pm 11.9$

$52.2 \pm 16.6$

$18.9 \pm 10.2$

$5.7 \pm 1.7$

$5.8 \pm 1.5$

$2.2 \pm 1.6$

$2.2 \pm 1.5$

$1.9 \pm 1.4$

38 (73.1)

8 (15.3)

\section{$3.9 \pm 0.9$}

$28.1 \pm 17.9$

$59.7 \pm 13.5$

$24.5 \pm 16.0$

$6.1 \pm 1.9$

$6.9 \pm 1.7$

$2.2 \pm 1.7$

$2.0 \pm 1.5$

$1.9 \pm 1.5$

93 (58.1)

13 (8.2)
$<0.001$

1.0

0.012

0.002

0.002

0.52

0.38

0.35

0.20

0.003

0.66

0.006

0.14

0.0

0.067

0.082

${ }^{a}$ Data available for 86 patients.

${ }^{b}$ Data available for 225 patients.

${ }^{\circ}$ Data available for 88 patients.

${ }^{d}$ Data available for 168 patients.

${ }^{e}$ Data available for 212 patients.

Bold values indicate $p<0.05$ for between-groups analysis.

TABLE 4 | Correlation between Structured Interview of Prodromal Syndromes (SIPS) symptom domains and functioning as well as severity of illness.

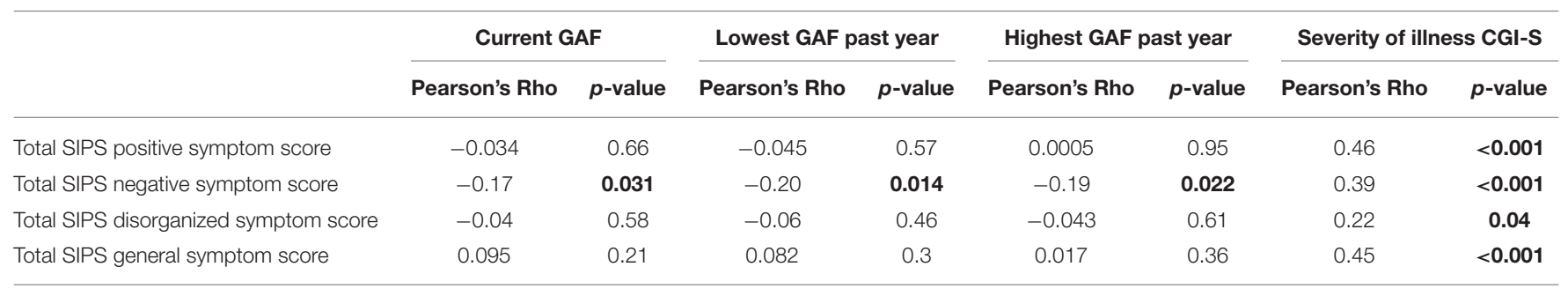

CGI-S, Clinical Global Impression-Severity scale; GAF, Global Assessment of Functioning; SIPS, Structured Interview for Psychosis-Risk Syndromes.

Bold values indicate $p<0.05$ for between-groups analysis.

TABLE 5 | Results of the multivariable, backward elimination logistic regression analysis of variables distinguishing APS vs. non-APS at $p<0.05$ in univariate analyses.

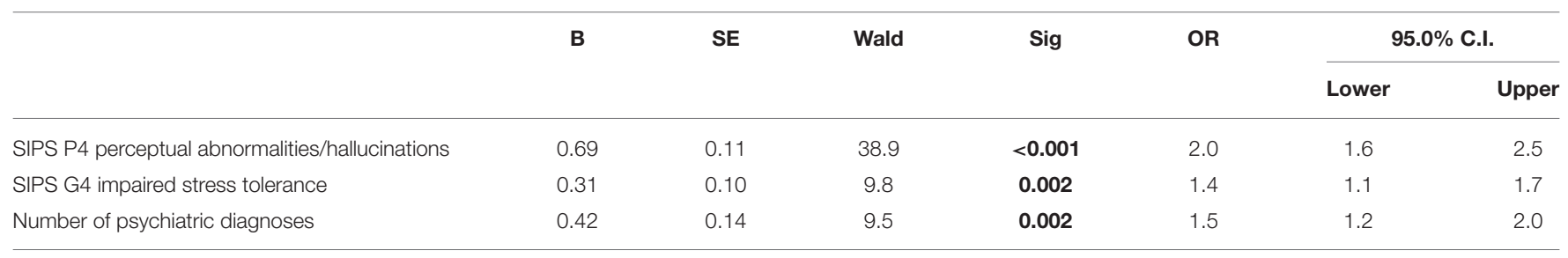

$\left(r^{2}=0.315, p<0.001\right)$.

Bold values indicate $p<0.05$ for between-groups analysis.

Thus, comorbidity should not rule out APS, but, if anything, increase the diagnostic suspicion. On the other hand, it is also possible for APS status to be a byproduct of overlapping disease processes and expressions of non-psychotic disorders, lowering the true risk for developing a psychotic disorder in the future $(22,28,70)$.

Regarding psychopharmacological treatment, as previously reported (22), a high percentage of our non-psychotic APS 
sample received atypical antipsychotics (66.1\%), which was also high in the non-psychotic non-APS individuals (49.4\%). This finding is worrying because no consistent meta-analytical evidence supports the use of atypical antipsychotic drugs in delaying or preventing transition to psychosis over other interventions $(71,72)$. However, it is also true that rates of antipsychotics were high in other diagnostic groups in this sample, including bipolar-spectrum disorders (49), which supports that atypical antipsychotic use is likely related to the reason for admission to the psychiatric unit and not only to efforts to treat attenuated psychotic symptoms or to prevent full-blown psychosis. Nevertheless, the widespread use of antipsychotics in adolescents for non-psychotic, predominantly depressive disorders is concerning due to the established adverse effects risks that atypical antipsychotics have in youth (73-77).

APS status was associated with a significantly higher severity of attenuated psychotic symptoms according to the SIPS. Effect sizes for these differences were moderate to large (Cohen's $\mathrm{d}=0.51$ to 1.5$)$. Regarding individual items, differences were found in 13/19 items. Effect sizes were large for unusual thought content, suspiciousness and perceptual abnormalities (Cohen's $\mathrm{d}=1.0$ to 1.3 ), medium for disorganized communication, social anhedonia, avolition, experience of emotions and self, bizarre thinking, trouble with focus and attention and impaired stress tolerance (Cohen's $d=0.50$ to 0.63 ), and small for grandiosity, sleep disturbances and dysphoric mood (Cohen's $d=0.34$ to 0.39 ).

This greater severity in psychopathology also translated into greater illness severity (Cohen's $d=1.0$ ) and poorer functioning (Cohen's $\mathrm{d}=0.31$ to 0.52 ), as found before $(9,22,78$, 79 ), including social functioning (Cohen's $d=0.66$ ), but not role functioning. However, a previous study using the same instruments found that both social and role functioning were significantly more impaired in CHR-P individuals compared to controls from as early as age 12 , which was our lower age limit (80). However, controls in that study were healthy, while in our sample, we compared hospitalized adolescents with vs. without APS who were likely admitted for symptoms related to other psychiatric disorders, which can explain the difficulties in role functioning as well as social and general functioning. The fact that all adolescents (APS and non-APS) reached stringent US criteria for inpatient care resulted in the low functioning scores found in both groups. Nevertheless, our results support previous evidence that APS status is associated with marked functional impairment $(21,81,82)$. This finding is particularly relevant because functional impairment can be helpful to differentiate youth meeting CHR-P from other help-seeking individuals (83).

Interestingly, while illness severity was associated with overall psychopathology, including more severe SIPS total positive, negative, disorganized and general symptoms (Pearson $\rho=-0.22$ to -0.46 ), functioning (current, lowest and highest) was only and weakly (Pearson $\rho=-0.17$ to $-0.20)$ correlated with total negative symptoms, but not with attenuated positive, disorganized and general symptoms. Negative symptoms have been associated with functioning (3840), not only in schizophrenia, but also in other psychotic individuals, and non-psychotic depressed patients (84). This association was found to be greater with negative than attenuated positive symptoms (85), in line with our results. In contrast, trauma has been found to be correlated with the severity of attenuated positive symptoms but not with negative symptoms in CHR-P individuals (86); yet, CHR-P individuals' negative symptoms may impact the transition to psychosis even more than attenuated positive symptoms (87), although this has not been found consistently (53).

According to our results, perceptual abnormalities $(\mathrm{OR}=2.0)$, number of psychiatric diagnoses $(\mathrm{OR}=1.5)$, and impaired stress tolerance $(\mathrm{OR}=1.4)$ were independently associated with APS status. Among perceptual abnormalities, auditory perceptual abnormalities have been associated with a higher risk of psychosis, while visual perceptual abnormalities have been associated with a lower risk (88). While the number of psychiatric diagnoses was independently associated with APS status in our study, and while APS has previously been associated with comorbid mental disorders, the impact of the different comorbid conditions may vary $(21,22)$. The most common comorbid conditions in our sample, anxiety and depressive diagnoses, have been associated with impaired global functioning, as well as higher suicidality or self-harm behaviors, but not with transition to psychosis (5). Implications of the presence of other comorbid conditions in APS and their relevance for true risk for conversion to psychosis need further study, particularly in adolescents. Our results further support previous evidence that impaired stress tolerance is a core CHR-P feature, which is associated with more severe psychopathology (89). The presence of impaired stress tolerance has been also suggested to have therapeutic implications in CHR-P (90).

We also found that APS was associated with functioning in univariate analyses, but not in multivariable analyses, supporting that lower functioning is related to other features, including the presence and duration of attenuated positive symptoms $(21,91)$ and impaired stress tolerance $(89)$. A model including disorganized communication, suspiciousness, verbal memory deficits, and decline in social functioning was found to predict conversion to psychosis (53). Due to having introduced the Global Functioning scales later into the study, they were only available in a subset of patients and could not be entered into the backward elimination logistic regression model. However, APS was associated with significantly lower levels of social functioning. Clinicians should thus monitor functioning, especially social functioning in adolescents with APS.

Finally, our results stress that in adolescent inpatients, DSM5 APS is associated with higher severity of overall illness, lower functioning and impaired stress tolerance, requiring a higher intensity of clinical care compared to non-APS adolescents admitted into an inpatient unit. This result is supported by prior findings showing that youth with APS have complex medical histories and frequent comorbidities that require therapeutic attention $(22,28,70)$. Research about effective treatments for DSM-5-APS has been limited (21), and evidence from studies analyzing CHR-P individuals-from which knowledge could arguably be applied to APS individuals-does not support one treatment over another (72). At the moment, at least needs-based interventions should be offered (9). Perceptual abnormalities and impaired stress tolerance may be targets of needs-based interventions in adolescents aiming to improve quality of life 
and aiming to reduce burden for them and their families. Still, prospective studies are needed to inform and develop guidelines regarding youth fulfilling APS criteria.

\section{Strengths and Limitations}

The current study has several strengths and limitations that must be taken into consideration when interpreting its results. First, some symptom assessments were based on retrospective recall, which may be prone to recall bias. However, all SIPS symptoms were rated for presence in the last month. Second, the comparison group, including non-psychotic adolescents who fulfilled criteria for inpatient care in the US health care system, was otherwise heterogeneous and functionally impaired. The results should thus be interpreted in the context of help-seeking APS and non-APS samples in need of inpatient care. Third, data were not available to determine to what degree adolescents with APS sought help specifically for APS-related symptomology. Fourth, we did not collect some potentially relevant information, including the reason for the use of psychotropic medications or dosage, which could have relevant implications. Similarly, verbal memory deficits and other cognitive measures, which are relevant according to previous research, were not included in the current analysis. Fifth, we could not retrieve the data for the total number of patients fulfilling our inclusion criteria within our study timeframe outside of this study. Thus, we could not report the participation rate. Sixth, we did not test for interrater reliability of interviewers for all scales used in this study. However, using the same training, certification and ongoing recalibration system via mandatory presence and presentation of all rating scale scores for all interviewers as part of the regular diagnostic consensus conference (led by the study PI CUC) the interrater reliability of the BPSS-FP indices ranged from intraclass-correlations of 0.93-0.98 (92). Seventh, since the Clinical Global Impressions of Severity Scale and social and role function scales were introduced later into the study, data were not available in a sufficiently large number of patients to enter this variable into the multivariable regression analysis; Eighth, the final model obtained from the multivariable regression analysis was not validated, which may have led to overfitting, thus requiring replication and limiting its generalizability and consequently its implementation in clinical practice. Finally, the cross-sectional design precludes any analysis of the predictive value of APS.

Nevertheless, despite these limitations, the study has several strengths. First, this is the largest study to date to comprehensively describe and characterize DSM-5-APS in adolescents. Second, we used structured and validated assessments that were carried out independently and face-to-face for both adolescents and their parents or caregivers to obtain as precise information as possible. These assessments were led by experienced and internally certified Master or MD level clinicians and psychologists. Third, we focused on individuals with a wide variety of psychopathology and treatment characteristics, both in the DSM-5-APS group and in the non-APS comparison group, increasing clinical value vs. comparisons with healthy control subjects. Finally, focusing on APS individuals allowed us to obtain results from a more homogeneous high-risk sample.

\section{CONCLUSIONS}

Approximately one in four adolescents hospitalized with nonpsychotic disorders meet DSM-5-APS criteria. These helpseeking adolescents have more comorbid psychiatric disorders as well as more severe symptoms, functional impairment and global severity of illness. Thus, they warrant high intensity clinical care. To what degree APS in adolescents with existing and emerging non-psychotic mental disorders is predictive of future transition to a psychotic disorder and what the predictors are for such transition requires further prospective study.

\section{DATA AVAILABILITY STATEMENT}

Datasets generated for this study are included in the article. Additional data might be shared upon request from the first or corresponding author.

\section{ETHICS STATEMENT}

The studies involving human participants were reviewed and approved by Institutional Review Board of the North ShoreLong Island Jewish Health System; Ethical Committee of Human Experimentation in the USA. Written informed consent to participate in this study was provided by the participants' legal guardian/next of kin.

\section{AUTHOR CONTRIBUTIONS}

GS had full access to all of the data in the study and takes responsibility for the integrity of the data and the accuracy of the data analysis. CC: study concept and design. GS, DG, BC, AA, RC, MC, SJ-F, DV, SW, MG, RS, NL, MB, and CC: acquisition of data. GS and CC: statistical analysis, drafting of the manuscript, administrative, technical, and material support. All authors critical revision of the manuscript for important intellectual content and interpretation of data.

\section{FUNDING}

This study was partially funded by a grant from the John and Maxine Bendheim Foundation (PI: CC). GS is supported by the Alicia Koplowitz Foundation. CM and CA have received support by the Spanish Ministry of Science and Innovation. Instituto de Salud Carlos III (PI17/02227), cofinanced by ERDF Funds from the European Commission, A way of making Europe, CIBERSAM. Madrid Regional Government (B2017/BMD-3740 AGES-CM-2), European Union Structural Funds. European Union Seventh Framework Program under grant agreements FP7-4-HEALTH-2009-2.2.1-2-241909 (Project EU-GEI), FP7- HEALTH-2013-2.2.1-2-603196 (Project PSYSCAN) and FP7- HEALTH-2013-2.2.1-2-602478 (Project METSY); and European Union H2020 Program under the Innovative Medicines Initiative 2 Joint Undertaking (grant agreement No. 115916, Project PRISM, and grant agreement No. 777394, Project AIMS-2-TRIALS), Fundación Familia Alonso, Fundación Alicia Koplowitz and Fundación Mutua Madrileña. 


\section{REFERENCES}

1. Yung AR, Yuen HP, Mcgorry PD, Phillips LJ, Kelly D, Dell'olio M, et al. Mapping the onset of psychosis: the comprehensive assessment of at-risk mental states. Aust N Z J Psychiatry. (2005) 39:964-71. doi: 10.1080/j.1440-1614.2005.01714.x

2. Fusar-Poli P, Borgwardt S, Bechdolf A, Addington J, RiecherRossler A, Schultze-Lutter F, et al. The psychosis high-risk state a comprehensive state-of-the-art review. JAMA Psychiatry. (2013) 70:107-20. doi: 10.1001/jamapsychiatry.2013.269

3. Falkenberg I, Valmaggia L, Byrnes $M$, Frascarelli $M$, Jones C, Rocchetti $M$, et al. Why are help-seeking subjects at ultra-high risk for psychosis help-seeking? Psychiatry Res. (2015) 228:808-15. doi: 10.1016/j.psychres.2015.05.018

4. Fusar-Poli P, Rocchetti M, Sardella A, Avila A, Brandizzi M, Caverzasi E, et al. Disorder, not just state of risk: meta-analysis of functioning and quality of life in people at high risk of psychosis. British J Psychiatry. (2015) 207:198-206. doi: 10.1192/bjp.bp.114.157115

5. Fusar-Poli P, Nelson B, Valmaggia L, Yung AR, Mcguire PK. Comorbid depressive and anxiety disorders in 509 individuals with an at-risk mental state: impact on psychopathology and transition to psychosis. Schizophr Bull. (2014) 40:120-31. doi: $10.1093 / \mathrm{schbul} / \mathrm{sbs} 136$

6. Boldrini T, Tanzilli A, Pontillo M, Chirumbolo A, Vicari S, Lingiardi V. Comorbid personality disorders in individuals with an at-risk mental state for psychosis: a meta-analytic review. Front Psychiatry. (2019) 10:429. doi: 10.3389/fpsyt.2019.00429

7. Fusar-Poli P, Mcgorry PD, Kane JM. Improving outcomes of firstepisode psychosis: an overview. World Psychiatry. (2017) 16:251-65. doi: 10.1002/wps.20446

8. Correll CU, Galling B, Pawar A, Krivko A, Bonetto C, Ruggeri M, et al. Comparison of early intervention services vs treatment as usual for early-phase psychosis: a systematic review, meta-analysis, and metaregression. JAMA Psychiatry. (2018) 75:555-65. doi: 10.1001/jamapsychiatry. 2018.0623

9. Fusar-Poli P, Salazar De Pablo G, Correll C, Meyer-Lindenberg A, Millan M, Borgwardt S, et al. Prevention of psychosis: advances in detection, prognosis and intervention. Jama Psychiatry. (2020) 77:755-65. doi: 10.1001/jamapsychiatry.2019.4779

10. Fusar-Poli P, Cappucciati M, Borgwardt S, Woods SW, Addington J, Nelson B, et al. Heterogeneity of psychosis risk within individuals at clinical high risk: a meta-analytical stratification. JAMA Psychiatry. (2016) 73:113-20. doi: 10.1001/jamapsychiatry.2015.2324

11. Fusar-Poli P, Cappucciati M, De Micheli A, Rutigliano G, Bonoldi I, Tognin $S$, et al. Diagnostic and prognostic significance of brief limited intermittent psychotic symptoms (BLIPS) in individuals at ultra high risk. Schizophr Bull. (2017) 43:48-56. doi: 10.1093/schbul/sbw151

12. Nelson B, Yuen K, Yung AR. Ultra high risk (UHR) for psychosis criteria: are there different levels of risk for transition to psychosis? Schizophr Res. (2011) 125:62-8. doi: 10.1016/j.schres.2010.10.017

13. Fusar-Poli P, De Micheli A, Chalambrides M, Singh A, Augusto C, Mcguire P. Unmet needs for treatment in 102 individuals with brief and limited intermittent psychotic symptoms (BLIPS): implications for current clinical recommendations. Epidemiol Psychiatr Sci. (2019) 29:e67. doi: $10.1017 /$ S2045796019000635

14. Minichino A, Rutigliano G, Merlino S, Davies C, Oliver D, De Micheli A, et al. Unmet needs in patients with brief psychotic disorders: too ill for clinical high risk services and not ill enough for first episode services. Eur Psychiatry. (2019) 57:26-32. doi: 10.1016/j.eurpsy.2018.12.006

15. Spada G, Molteni S, Pistone C, Chiappedi M, Mcguire P, Fusar-Poli P, et al. Identifying children and adolescents at ultra high risk of psychosis in Italian neuropsychiatry services: a feasibility study. Eur Child Adolesc Psychiatry. (2016) 25:91-106. doi: 10.1007/s00787-015-0710-8

16. Millman ZB, Pitts SC, Thompson E, Kline ER, Demro C, Weintraub MJ, et al. Perceived social stress and symptom severity among help-seeking adolescents with versus without clinical high-risk for psychosis. Schizophr Res. (2018) 192:364-70. doi: 10.1016/j.schres.2017.06.002

17. D’angelo EJ, Morelli N, Lincoln SH, Graber K, Tembulkar S, Gaudet $\mathrm{A}$, et al. Social impairment and social language deficits in children and adolescents with and at risk for psychosis. Schizophr Res. (2019) 204:304-10. doi: 10.1016/j.schres.2018.07.028

18. Miller T, Mcglashan T, Woods S, Stein K, Driesen N, Corcoran C, et al. Symptom assessment in schizophrenic prodromal states. Psychiatr $Q$ Winter. (1999) 70:273-87. doi: 10.1023/A:1022034115078

19. Miller T, Mcglashan T, Rosen J, Cadenhead K, Cannon T, Ventura J, et al. Prodromal assessment with the structured interview for prodromal syndromes and the scale of prodromal symptoms: predictive validity, interrater reliability, and training to reliability. Schizophr Bull. (2003) 29:70315. doi: 10.1093/oxfordjournals.schbul.a007040

20. Fusar-Poli P, Cappucciati M, Rutigliano G, Schultze-Lutter F, Bonoldi I, Borgwardt S, et al. At risk or not at risk? A meta-analysis of the prognostic accuracy of psychometric interviews for psychosis prediction. World Psychiatry. (2015) 14:322-32. doi: 10.1002/wps.20250

21. Salazar De Pablo G, Catalan A, Fusar-Poli P. Clinical validity of DSM-5 attenuated psychosis syndrome: advances in diagnosis, prognosis, and treatment. JAMA Psychiatry. (2019) 77:311-20. doi: 10.1001 /jamapsychiatry.2019.3561

22. Gerstenberg M, Hauser M, Al-Jadiri A, Sheridan EM, Kishimoto T, Borenstein $\mathrm{Y}$, et al. Frequency and correlates of DSM-5 attenuated psychosis syndrome in a sample of adolescent inpatients with nonpsychotic psychiatric disorders. $J$ Clin Psychiatry. (2015) 76:1449-58. doi: 10.4088/JCP.14m09435

23. American Psychiatric Association. Diagnostic and Statistical Manual of Mental Disorders. Washington, DC: American Psychiatric Association. (2013). doi: 10.1176/appi.books. 9780890425596

24. Tsuang MT, Van Os J, Tandon R, Barch DM, Bustillo J, Gaebel W, et al. Attenuated psychosis syndrome in DSM-5. Schizophr Res. (2013) 150:31-5. doi: 10.1016/j.schres.2013.05.004

25. Fusar-Poli P, De Micheli A, Cappucciati M, Rutigliano G, Davies C, RamellaCravaro V, et al. Diagnostic and prognostic significance of DSM-5 attenuated psychosis syndrome in services for individuals at ultra high risk for psychosis. Schizophr Bull. (2018) 44:264-75. doi: 10.1093/schbul/sbx055

26. Cakmak S, Karaytug MO, Bal U, Tamam L, Tasdemir A. Retrospective evaluation of risk determinants in prodromal period with a group of schizophrenia patients. Cukurova Med J. (2016) 41:437-46. doi: 10.17826/cukmedj.234960

27. Zoghbi AW, Bernanke JA, Gleichman J, Masucci MD, Corcoran CM, Califano A, et al. Schizotypal personality disorder in individuals with the Attenuated Psychosis Syndrome: frequent co-occurrence without an increased risk for conversion to threshold psychosis. J Psychiatr Res. (2019) 114:88-92. doi: 10.1016/j.jpsychires.2019.04.018

28. Gerstenberg M, Theodoridou A, Traber-Walker N, Franscini M, Wotruba D, Metzler S, et al. Adolescents and adults at clinical high-risk for psychosis: age-related differences in attenuated positive symptoms syndrome prevalence and entanglement with basic symptoms. Psychol Med. (2016) 46:1069-78. doi: $10.1017 /$ S0033291715002627

29. Brucato G, Masucci MD, Arndt LY, Ben-David S, Colibazzi T, Corcoran $\mathrm{CM}$, et al. Baseline demographics, clinical features and predictors of conversion among 200 individuals in a longitudinal prospective psychosisrisk cohort. Psychol Med. (2017) 47:1923-35. doi: 10.1017/S00332917170 00319

30. Lu Y, Marshall C, Cadenhead KS, Cannon TD, Cornblatt BA, Mcglashan $\mathrm{TH}$, et al. Perceptual abnormalities in clinical high risk youth and the role of trauma, cannabis use and anxiety. Psychiatry Res. (2017) 258:462-8. doi: 10.1016/j.psychres.2017.08.045

31. Arango C. Attenuated psychotic symptoms syndrome: how it may affect child and adolescent psychiatry. Eur Child Adolesc Psychiatry. (2011) 20:67-70. doi: 10.1007/s00787-010-0144-2

32. Ziermans TB, Schothorst PF, Sprong M, Van Engeland H. Transition and remission in adolescents at ultra-high risk for psychosis. Schizophr Res. (2011) 126:58-64. doi: 10.1016/j.schres.2010.10.022

33. Manninen $M$, Lindgren $M$, Therman S, Huttunen $M$, Ebeling $H$, Moilanen I, et al. Clinical high-risk state does not predict later psychosis in a delinquent adolescent population. Early Interv Psychiatry. (2014) 8:87-90. doi: 10.1111/eip. 12045

34. Koren D, Scheyer R, Stern Y, Adres M, Reznik N, Apter A, et al. Metacognition strengthens the association between neurocognition and attenuated psychosis syndrome: preliminary evidence from a pilot study 
among treatment-seeking versus healthy adolescents. Schizophr Res. (2019) 210:207-14. doi: 10.1016/j.schres.2018.12.036

35. Ribolsi M, Lin A, Wardenaar KJ, Pontillo M, Mazzone L, Vicari S, et al. Clinical presentation of attenuated psychosis syndrome in children and adolescents: is there an age effect? Psychiatry Res. (2017) 252:169-74. doi: 10.1016/j.psychres.2017.02.050

36. Carrion RE, Mclaughlin D, Goldberg TE, Auther AM, Olsen RH, Olvet DM, et al. Prediction of functional outcome in individuals at clinical high risk for psychosis. JAMA Psychiatry. (2013) 70:1133-42. doi: 10.1001/jamapsychiatry.2013.1909

37. Asher L, Zammit S, Sullivan S, Dorrington S, Heron J, Lewis G. The relationship between psychotic symptoms and social functioning in a non-clinical population of 12 year olds. Schizophr Res. (2013) 150:404-9. doi: 10.1016/..schres.2013.08.031

38. Ventura J, Subotnik KL, Gitlin MJ, Gretchen-Doorly D, Ered A, Villa KF, et al. Negative symptoms and functioning during the first year after a recent onset of schizophrenia and 8 years later. Schizophr Res. (2015) 161:407-13. doi: 10.1016/j.schres.2014.10.043

39. Erickson M, Jaafari N, Lysaker P. Insight and negative symptoms as predictors of functioning in a work setting in patients with schizophrenia. Psychiatry Res. (2011) 189:161-5. doi: 10.1016/j.psychres.2011.06.019

40. Rocca $\mathrm{P}$, Montemagni $\mathrm{C}$, Zappia $\mathrm{S}$, Piterà R, Sigaudo $\mathrm{M}$, Bogetto $\mathrm{F}$. Negative symptoms and everyday functioning in schizophrenia: a crosssectional study in a real world-setting. Psychiatry Res. (2014) 218:284-9. doi: 10.1016/j.psychres.2014.04.018

41. Perkins DO, Jeffries CD, Cornblatt BA, Woods SW, Addington J, Bearden $\mathrm{CE}$, et al. Severity of thought disorder predicts psychosis in persons at clinical high-risk. Schizophr Res. (2015) 169:169-77. doi: 10.1016/j.schres.2015.09.008

42. Ciarleglio AJ, Brucato G, Masucci MD, Altschuler R, Colibazzi T, Corcoran $\mathrm{CM}$, et al. A predictive model for conversion to psychosis in clinical high-risk patients. Psychol Med. (2019) 49:1128-37. doi: 10.1017/S003329171800171X

43. Fusar-Poli P, Davies C, Rutigliano G, Stahl D, Bonoldi I, Mcguire P. Transdiagnostic individualized clinically based risk calculator for the detection of individuals at risk and the prediction of psychosis: model refinement including nonlinear effects of age. Front Psychiatry. (2019) 10:313. doi: $10.3389 /$ fpsyt.2019.00313

44. Fusar-Poli P, Werbeloff N, Rutigliano G, Oliver D, Davies C, Stahl D, et al. Transdiagnostic risk calculator for the automatic detection of individuals at risk and the prediction of psychosis: second replication in an Independent National Health Service Trust. Schizophr Bull. (2019) 45:562-70. doi: 10.1093/schbul/sby070

45. Malda A, Boonstra N, Barf H, De Jong S, Aleman A, Addington J, et al. Individualized prediction of transition to psychosis in 1,676 individuals at clinical high risk: development and validation of a multivariable prediction model based on individual patient data meta-analysis. Front Psychiatry. (2019) 10:345. doi: 10.3389/fpsyt.2019.00345

46. Cannon TD, Yu C, Addington J, Bearden CE, Cadenhead KS, Cornblatt BA, et al. An individualized risk calculator for research in prodromal psychosis. Am J Psychiatry. (2016) 173:980-8. doi: 10.1176/appi.ajp.2016.15070890

47. Oliver D, Reilly TJ, Baccaredda Boy O, Petros N, Davies C, Borgwardt S, et al. What causes the onset of psychosis in individuals at clinical high risk? A meta-analysis of risk and protective factors. Schizophr Bull. (2019) 46:110-20. doi: $10.1093 /$ schbul/sbz039

48. Lo Cascio N, Saba R, Hauser M, Vernal DL, Al-Jadiri A, Borenstein Y, et al. Attenuated psychotic and basic symptom characteristics in adolescents with ultra-high risk criteria for psychosis, other non-psychotic psychiatric disorders and early-onset psychosis. Eur Child Adolesc Psychiatry. (2016) 25:1091-102. doi: 10.1007/s00787-016-0832-7

49. Salazar De Pablo G, Guinart D, Cornblatt B, Auther A, Carrión R, Carbon $\mathrm{M}$, et al. Demographic and clinical characteristics, including subsyndromal symptoms across bipolar-spectrum disorders in adolescents. JCAP. (2020) 30:222-234. doi: 10.1089/cap.2019.0138

50. First M, Williams J, Karg R, Spitzer R. Structured Clinical Interview for DSM-5-Research Version (SCID-5 for DSM-5, Research Version; SCID-5-RV). Arlington, VA: American Psychiatric Association. (2015).

51. Kaufman J, Birmaher B, Brent D, Rao U, Flynn C, Moreci P, et al. Schedule for affective disorders and schizophrenia for school-age children-present and lifetime version (K-SADS-PL): initial reliability and validity data. J Am Acad Child Adolesc Psychiatry. (1997) 36:980-8. doi: 10.1097/00004583-199707000-00021

52. Mcglashan TWB, Woods S. The Psychosis-Risk Syndrome: Handbook for Diagnosis and Follow-Up: Oxford: Oxford University. (2010).

53. Cornblatt BA, Carrion RE, Auther A, Mclaughlin D, Olsen RH, John M, et al. Psychosis prevention: a modified clinical high risk perspective from the recognition and prevention (RAP) program. Am J Psychiatry. (2015) 172:986-94. doi: 10.1176/appi.ajp.2015.13121686

54. Busner J, Targum SD. The clinical global impressions scale: applying a research tool in clinical practice. Psychiatry. (2007) 4:28-37.

55. Piersma HL, Boes JL. The GAF and psychiatric outcome: a descriptive report. Community Ment Health J. (1997) 33:35-41. doi: 10.1023/A:1022413110345

56. Cornblatt BA, Auther AM, Niendam T, Smith CW, Zinberg J, Bearden CE, et al. Preliminary findings for two new measures of social and role functioning in the prodromal phase of schizophrenia. Schizophr Bull. (2007) 33:688-702. doi: $10.1093 / \mathrm{schbul} / \mathrm{sbm} 029$

57. Carrión RE, Auther AM, Mclaughlin D, Olsen R, Addington J, Bearden CE, et al. The global functioning: social and role scales-further validation in a large sample of adolescents and young adults at clinical high risk for psychosis. Schizophr Bull. (2019) 45:763-72. doi: 10.1093/schbul/sby126

58. Agrawal S, Bhat RS, Kuruvilla K. Validity of the scale to assess unawareness of mental disorder. Am J Psychiatry. (1994) 151:1843-4. doi: 10.1176/ajp.151.12.1843

59. Cramér H. Mathematical Methods of Statistics. Princeton: Princeton University Press. (1946)

60. Cohen J. Statistical Power Analysis for the Behavioral Sciences. New York, NY: Routledge Academic. (1988).

61. Daniel T, Kostic B. Effect Size Calculator for $t$ Tests. (2019). Retrieved from: $\quad$ https://drive.google.com/drive/folders/1n9aCsq5j4dQ6m sv62ohDI69aol3rW6Q? usp=sharing.

62. Ibm Corp. IBM SPSS Statistics for Macintosh, Version 21.0. Armonk, NY: IBM Corp. (2012),

63. Birmaher B, Axelson D, Strober M, Gill MK, Valeri S, Chiappetta L, et al. Clinical course of children and adolescents with bipolar spectrum disorders. Arch Gen Psychiatry. (2006) 63:175-83. doi: 10.1001/archpsyc.63.2.175

64. Lindgren M, Manninen M, Laajasalo T, Mustonen U, Kalska H, Suvisaari J, et al. The relationship between psychotic-like symptoms and neurocognitive performance in a general adolescent psychiatric sample. Schizophr Res. (2010) 123:77-85. doi: 10.1016/j.schres.2010.07.025

65. Lindgren M, Manninen M, Kalska H, Mustonen U, Laajasalo T, Moilanen $\mathrm{K}$, et al. Predicting psychosis in a general adolescent psychiatric sample. Schizophr Res. (2014) 158:1-6. doi: 10.1016/j.schres.2014.06.028

66. Linscott RJ, Van Os J. An updated and conservative systematic review and meta-analysis of epidemiological evidence on psychotic experiences in children and adults: on the pathway from proneness to persistence to dimensional expression across mental disorders. Psychol Med. (2013) 43:1133-49. doi: 10.1017/S0033291712001626

67. Gur RC, Calkins ME, Satterthwaite TD, Ruparel K, Bilker WB, Moore TM, et al. Neurocognitive growth charting in psychosis spectrum youths. JAMA Psychiatry. (2014) 71:366-74. doi: 10.1001/jamapsychiatry.2013.4190

68. Simeonova DI, Lee FJ, Walker EF. Longitudinal investigation of the relationship between family history of psychosis and affective disorders and Child Behavior Checklist ratings in clinical high-risk adolescents. Schizophr Res. (2015) 166:24-30. doi: 10.1016/j.schres.2015.04.027

69. Addington J, Piskulic D, Liu L, Lockwood J, Cadenhead KS, Cannon TD, et al. Comorbid diagnoses for youth at clinical high risk of psychosis. Schizophr Res. (2017) 190:90-5. doi: 10.1016/j.schres.2017.03.043

70. Schimmelmann BG, Michel C, Martz-Irngartinger A, Linder C, SchultzeLutter F. Age matters in the prevalence and clinical significance of ultra-highrisk for psychosis symptoms and criteria in the general population: findings from the BEAR and BEARS-kid studies. World Psychiatry. (2015) 14:189-97. doi: 10.1002/wps.20216

71. Stafford MR, Jackson H, Mayo-Wilson E, Morrison AP, Kendall T. Early interventions to prevent psychosis: systematic review and meta-analysis. Bmj-British Med J. (2013) 346:f185. doi: 10.1136/bmj.f185

72. Davies C, Cipriani A, Ioannidis JPA, Radua J, Stahl D, Provenzani U, et al. Lack of evidence to favor specific preventive interventions in psychosis: a network meta-analysis. World Psychiatry. (2018) 17:196-209. doi: 10.1002/wps.20526 
73. De Hert M, Dobbelaere M, Sheridan EM, Cohen D, Correll CU. Metabolic and endocrine adverse effects of second-generation antipsychotics in children and adolescents: a systematic review of randomized, placebo controlled trials and guidelines for clinical practice. Eur Psychiatry. (2011) 26:144-58. doi: 10.1016/j.eurpsy.2010.09.011

74. Carbon M, Kapoor S, Sheridan E, Al-Jadiri A, Azzo S, Sarkaria T, et al. Neuromotor adverse effects in 342 youth during 12 weeks of naturalistic treatment with 5 second-generation antipsychotics. J Am Acad Child Adolesc Psychiatry. (2015) 54:718-27.e713. doi: 10.1016/j.jaac.2015. 06.015

75. Al-Dhaher Z, Kapoor S, Saito E, Krakower S, David L, Ake T, et al. Activating and tranquilizing effects of first-time treatment with aripiprazole, olanzapine, quetiapine, and risperidone in youth. J Child Adolesc Psychopharmacol. (2016) 26:458-70. doi: 10.1089/cap.2015.0141

76. Galling B, Roldán A, Nielsen RE, Nielsen J, Gerhard T, Carbon M, et al. Type 2 diabetes mellitus in youth exposed to antipsychotics: a systematic review and meta-analysis. JAMA Psychiatry. (2016) 73:247-59. doi: 10.1001/jamapsychiatry.2015.2923

77. Solmi M, Fornaro M, Ostinelli E, Zangani C, Croatto G, Monaco F, et al. Safety of 80 antidepressants, antipsychotics, anti-attention-deficit/hyperactivity medications and mood stabilizers in children and adolescents with psychiatric disorders: a large scale systematic meta-review of 78 adverse effects. World Psychiatry. (2020) 19:214-32. doi: 10.1002/wps.20765

78. Rapado-Castro M, Mcgorry PD, Yung A, Calvo A, Nelson B. Sources of clinical distress in young people at ultra high risk of psychosis. Schizophr Res. (2015) 165:15-21. doi: 10.1016/j.schres.2015.03.022

79. Dolz M, Tor J, Portoles L, Pardo M, Munoz-Samons D, Rodriguez-Pascual M, et al. Children and adolescents at risk for psychosis: transition and baseline characteristics. Early Interv Psychiatry. (2018) 12:187-187.

80. Velthorst E, Zinberg J, Addington J, Cadenhead KS, Cannon TD, Carrion RE, et al. Potentially important periods of change in the development of social and role functioning in youth at clinical high risk for psychosis. Dev Psychopathol. (2018) 30:39-47. doi: 10.1017/S0954579417000451

81. Kelleher I, Murtagh A, Molloy C, Roddy S, Clarke MC, Harley M, et al. Identification and characterization of prodromal risk syndromes in young adolescents in the community: a population-based clinical interview study. Schizophr Bull. (2012) 38:239-46. doi: 10.1093/schbul/ sbr164

82. Gaudiano BA, Zimmerman M. Prevalence of attenuated psychotic symptoms and their relationship with DSM-IV diagnoses in a general psychiatric outpatient clinic. J Clin Psychiatry. (2013) 74:149-55. doi: 10.4088/JCP.12m07788

83. Lo Cascio N, Curto M, Pasqualetti P, Lindau JF, Girardi N, Saba R, et al. Impairment in Social Functioning differentiates youth meeting UltraHigh Risk for psychosis criteria from other mental health help-seekers: a validation of the Italian version of the Global Functioning: social and global functioning: role scales. Psychiatry Res. (2017) 253:296-302. doi: 10.1016/j.psychres.2017.04.008

84. Herbener ES, Harrow M. Are negative symptoms associated with functioning deficits in both schizophrenia and nonschizophrenia patients? A 10-year longitudinal analysis. Schizophr Bull. (2004) 30:813-25. doi: 10.1093/oxfordjournals.schbul.a007134

85. Rabinowitz J, Levine SZ, Garibaldi G, Bugarski-Kirola D, Berardo CG, Kapur S. Negative symptoms have greater impact on functioning than positive symptoms in schizophrenia: analysis of CATIE data. Schizophr Res. (2012) 137:147-50. doi: 10.1016/j.schres.2012.01.015

86. Kline E, Millman ZB, Denenny D, Wilson C, Thompson E, Demro C, et al. Trauma and psychosis symptoms in a sample of help-seeking youth. Schizophr Res. (2016) 175:174-9. doi: 10.1016/j.schres.2016.04.006
87. Valmaggia LR, Stahl D, Yung AR, Nelson B, Fusar-Poli P, Mcgorry PD, et al. Negative psychotic symptoms and impaired role functioning predict transition outcomes in the at-risk mental state: a latent class cluster analysis study. Psychol Med. (2013) 43:2311-25. doi: 10.1017/S0033291713000251

88. Lehembre-Shiah E, Leong W, Brucato G, Abi-Dargham A, Lieberman JA, Horga G, et al. Distinct relationships between visual and auditory perceptual abnormalities and conversion to psychosis in a clinical high-risk population. JAMA Psychiatry. (2017) 74:104-6. doi: 10.1001/jamapsychiatry.2016.3055

89. Devylder JE, Ben-David S, Schobel SA, Kimhy D, Malaspina D, Corcoran CM. Temporal association of stress sensitivity and symptoms in individuals at clinical high risk for psychosis. Psychol Med. (2013) 43:259-68. doi: 10.1017/S0033291712001262

90. Mcausland L, Addington J. Biofeedback to treat anxiety in young people at clinical high risk for developing psychosis. Early Interv Psychiatry. (2018) 12:694-701. doi: 10.1111/eip.12368

91. Carrion RE, Demmin D, Auther AM, Mclaughlin D, Olsen R, Lencz $\mathrm{T}$, et al. Duration of attenuated positive and negative symptoms in individuals at clinical high risk: associations with risk of conversion to psychosis and functional outcome. J Psychiatr Res. (2016) 81:95-101. doi: 10.1016/j.jpsychires.2016.06.021

92. Correll CU, Olvet DM, Auther AM, Hauser M, Kishimoto T, Carrión RE, et al. The Bipolar Prodrome Symptom Interview and Scale-Prospective (BPSS$\mathrm{P})$ : description and validation in a psychiatric sample and healthy controls. Bipolar Disord. (2014) 16:505-22. doi: 10.1111/bdi.12209

Conflict of Interest: DG has been a consultant for and/or has received speaker honoraria from Otsuka America and Janssen Pharmaceuticals. DV has received speaking fees from Lundbeck. SW has received in the last 5 years royalties from Thieme Hogrefe, Kohlhammer, Springer, Beltz. Outside professional activities and interests are declared under the link of the University of Zurich https:// www.uzh.ch/prof/apps/interessenbindungen/client/. CA has been a consultant to or has received honoraria or grants from Acadia, Ambrosseti, Gedeon Richter, Janssen Cilag, Lundbeck, Otsuka, Roche, Sage, Servier, Shire, Schering Plow, Sumitomo Dainippon Pharma, Sunovion and Takeda. CM has acted as consultant or participated in DMC for Janssen, Servier, Lundbeck, Nuvelution, Angelini and Otsuka. PF-P has received grants and personal fees from Lundbeck and personal fees from Menarini. CC has been a consultant and/or advisor to or has received honoraria from: Acadia, Alkermes, Allergan, Angelini, Axsome, Gedeon Richter, Gerson Lehrman Group, IntraCellular Therapies, Janssen/J\&J, LB Pharma, Lundbeck, MedAvante-ProPhase, Medscape, Neurocrine, Noven, Otsuka, Pfizer, Recordati, Rovi, Sumitomo Dainippon, Sunovion, Supernus, Takeda, and Teva. He has provided expert testimony for Bristol-Myers Squibb, Janssen, and Otsuka. He served on a Data Safety Monitoring Board for Lundbeck, Rovi, Supernus, and Teva. He received royalties from UpToDate and grant support from Janssen and Takeda. He is also a shareholder of LB Pharm.

The remaining authors declare that the research was conducted in the absence of any commercial or financial relationships that could be construed as a potential conflict of interest.

Copyright (c) 2020 Salazar de Pablo, Guinart, Cornblatt, Auther, Carrión, Carbon, Jiménez-Fernández, Vernal, Walitza, Gerstenberg, Saba, Lo Cascio, Brandizzi, Arango, Moreno, Van Meter, Fusar-Poli and Correll. This is an open-access article distributed under the terms of the Creative Commons Attribution License (CC BY). The use, distribution or reproduction in other forums is permitted, provided the original author(s) and the copyright owner(s) are credited and that the original publication in this journal is cited, in accordance with accepted academic practice. No use, distribution or reproduction is permitted which does not comply with these terms. 